Check for updates

Cite this: RSC Adv., 2017, 7, 41771

Received 5th June 2017

Accepted 6th August 2017

DOI: $10.1039 / \mathrm{c} 7 \mathrm{ra06252d}$

rsc.li/rsc-advances

\section{Silver particle-loaded nickel oxide nanosheet arrays on nickel foam as advanced binder-free electrodes for aqueous asymmetric supercapacitors $\dagger$}

\author{
Shuxing Wu, ${ }^{a}$ Kwan San Hui, (D) ${ }^{b}$ Kwun Nam Hui, (D) ${ }^{c}$ Je Moon Yun (D) d \\ and Kwang Ho Kim (iD *ad
}

Conductive metal loading is an efficient approach for enhancing the electric conductivity of redox-active transition-metal oxide electrodes. In this study, Ag particle-loaded NiO/nickel foam (Ag-NiO/NF) composites were fabricated using a green chemistry method. The anchored Ag particles standing on the surface of $\mathrm{NiO}$ nanosheet arrays helped improve the electrical conductivity and were thus beneficial for supercapacitors (SCs). The as-developed Ag-NiO/NF electrode delivered a specific capacitance of $1254.9 \mathrm{~F} \mathrm{~g}^{-1}$ at the current density of $1 \mathrm{~A} \mathrm{~g}^{-1}$, which is higher than that of $\mathrm{NiO} / \mathrm{NF}$ electrode $\left(946.3 \mathrm{~F} \mathrm{~g}^{-1}\right.$ ). Using such $\mathrm{Ag}-\mathrm{NiO} / \mathrm{NF}$ as a positive electrode, we further fabricated aqueous asymmetric SC devices with reduced graphene oxide as a negative electrode. Owing to the efficient electron transport and short ion diffusion paths in the designed electrode, the devices exhibited a high specific capacitance of $97.9 \mathrm{~F} \mathrm{~g}$ at $1 \mathrm{~A} \mathrm{~g}^{-1}$ with a high energy density of $26.7 \mathrm{~W} \mathrm{~h} \mathrm{~kg}^{-1}$ at a power density of 1017.1 $\mathrm{W} \mathrm{kg}^{-1}$ and great cyclic stability.

\section{Introduction}

In recent years, supercapacitors (SCs) have received increasing attention due to their high power density, fast charge/discharge rate, and long cycle life. SCs can be divided into two categories based on their energy storage mechanism: electrical doublelayer capacitors (EDLCs) and pseudocapacitors. EDLCs store charge at the electrode/electrolyte interface via reversible ion adsorption on high-surface-area electrode materials such as activated carbon, carbon nanotube (CNT), and graphene. ${ }^{1}$ Pseudocapacitors use fast and reversible surface or near-surface reactions for charge storage. ${ }^{2}$ Pseudocapacitors can exhibit approximately 10-100 times higher capacitance than EDLCs. ${ }^{3}$ The electrochemical performance of SCs mainly depends on their electrode materials. Therefore, the development of advanced electrode materials has become an active research field in the areas of SCs.

Transition metal oxides (such as $\mathrm{NiO}, \mathrm{Co}_{3} \mathrm{O}_{4}, \mathrm{MnO}_{2}$, and $\mathrm{V}_{2} \mathrm{O}_{5}$ ), polyoxometalates (such as $\mathrm{NiCo}_{2} \mathrm{O}_{4}$ and $\mathrm{MnCo}_{2} \mathrm{O}_{4}$ ), and

${ }^{a}$ School of Materials Science and Engineering, Pusan National University, San 30 Jangjeon-dong, Geumjeong-gu, Busan 609-735, Republic of Korea. E-mail: kwhokim@pusan.ac.kr; Fax: +82 51514 4; Tel: +82 515103391

${ }^{b}$ School of Mathematics, University of East Anglia, Norwich NR4 7TJ, UK

'Institute of Applied Physics and Materials Engineering, University of Macau, Avenida da Universidade, Taipa, Macau, China

${ }^{d}$ Global Frontier R\&D Center for Hybrid Interface Materials, Pusan National University, 30 Jangjeon-dong, Geumjung-gu, Busan 609-735, South Korea

† Electronic supplementary information (ESI) available. See DOI: 10.1039/c7ra06252d electronically conducting polymers (such as polyaniline as polypyrrole) have been widely investigated because of their high energy density. ${ }^{4-8} \mathrm{NiO}$ has attracted significant attention due to its intriguing characteristics such as ultrahigh theoretical specific capacitance $\left(2584 \mathrm{~F} \mathrm{~g}^{-1}\right)$, environmental friendliness, low cost, abundance on earth, and ease and wide range of fabrication strategies. ${ }^{7,9-11}$ However, NiO shows low electrical conductivity $\left(\sim 10^{-4} \mathrm{~S} \mathrm{~cm}^{-1}\right)$ and experiences large volume change during the charge/discharge process. ${ }^{12}$ Considerable research effort has been devoted to prepare new composite structures to resolve these problems; for example, NiO is combined with highly conductive materials, including active carbon, ${ }^{13,14}$ CNT, ${ }^{15,16}$ and graphene. ${ }^{17}$ However, these methods usually involve the use of polymer binders. The addition of polymer binder will inevitably increase the "dead volume" and "dead weight" in electrode materials. ${ }^{18,19}$ An ideal scheme is the use of binder-free (self-supported) electrodes, which are constructed by direct integration of electroactive materials on current collectors, such as nickel foam..$^{20}$ Improved cycle life and rate capability are achieved through fabricating NiO-based binder-free electrodes, but the capacitances are still low. Gonzalez et al. prepared $\mathrm{NiO} /$ nickel foam by use of a simple, green, and cost-effective electrophoretic deposition, thereby obtaining a low specific capacitance of $192 \mathrm{~F} \mathrm{~g}^{-1} .^{21}$

The performance of SCs can be enhanced by compositing the $\mathrm{NiO} /$ nickel foam with noble metals, such as $\mathrm{Pt}, \mathrm{Au}$, and $\mathrm{Ag}$. $\mathrm{Ag}$ loaded composites have received much interest because $\mathrm{Ag}$ is more electrically conductive and low cost compared with Au and Pt. As a noble metal, Ag particles can produce electron transfer 

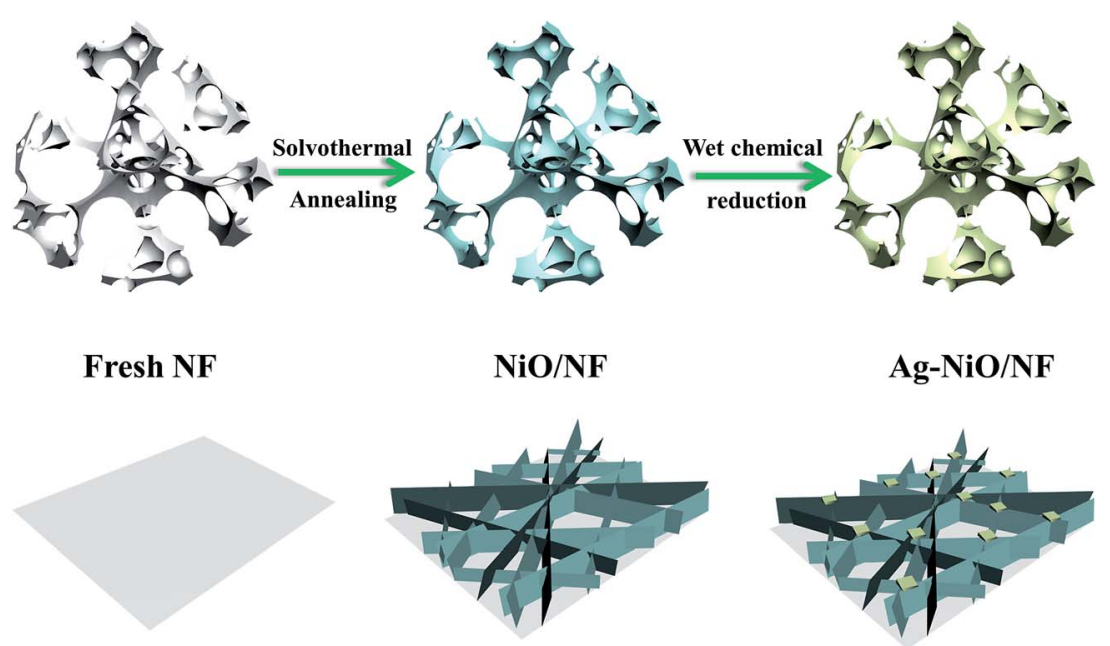

Scheme 1 Schematic of the fabrication procedures of $\mathrm{Ag}-\mathrm{NiO} / \mathrm{NF}$.

channels because of their outstanding electronic conductivity and durability. ${ }^{22,23}$ They also enhance the proton $\left(\mathrm{H}^{+}\right)$diffusion throughout the electrode..$^{24}$ Vanitha et al. prepared $\mathrm{Ag}$ anchored $\mathrm{CeO}_{2}$ /graphene nanocomposite; the nanocomposite electrode shows a high specific capacitance of $710.42 \mathrm{~F} \mathrm{~g}^{-1}$ at current density of $0.2 \mathrm{~A} \mathrm{~g}^{-1}$, which is nearly twofold higher than $\mathrm{CeO}_{2} /$ graphene nanocomposite. ${ }^{25} \mathrm{Ma}$ et al. synthesized $\mathrm{Ag} / \mathrm{MnO}_{2} /$ graphene ternary nanocomposite; the ternary nanocomposite exhibits high specific capacitance of $467 \mathrm{~F} \mathrm{~g}^{-1}$, which is much higher than that of $\mathrm{MnO}_{2} /$ graphene nanocomposite $\left(293 \mathrm{~F} \mathrm{~g}^{-1}\right){ }^{26}$

In this study, we synthesized interconnected NiO nanosheets supported by nickel foam (NiO/NF) through a facile solvothermal method combined with a post-annealing process. Ag particles were loaded on the $\mathrm{NiO} / \mathrm{NF}$ by use of a wet chemical reduction method of aqueous $\mathrm{AgNO}_{3}$ solution. Scheme 1 shows a schematic of the fabrication process. Significant improvement was obtained after the loading of $\mathrm{Ag}$ particles. The Ag particleloaded NiO/nickel foam (Ag-NiO/NF) electrode exhibited high specific capacitance $\left(1254.9 \mathrm{~F} \mathrm{~g}^{-1}\right.$ at $1 \mathrm{~A} \mathrm{~g}^{-1}$ and $914.3 \mathrm{~F} \mathrm{~g}^{-1}$ at $\left.20 \mathrm{~A} \mathrm{~g}^{-1}\right)$ and good cycling stability (83.2\% capacitance retention over 3000 cycles). Asymmetric SCs, which were comprised of $\mathrm{Ag}-\mathrm{NiO} / \mathrm{NF}$ as the positive electrode, reduced graphene oxide $(\mathrm{rGO})^{7}$ as the negative electrode, and $6 \mathrm{M} \mathrm{KOH}$ aqueous solution as the electrolyte, were fabricated. The aqueous asymmetric SCs yielded a high specific capacitance of $97.9 \mathrm{~F} \mathrm{~g}$ at $1 \mathrm{~A} \mathrm{~g}^{-1}$ and a specific energy density of $26.7 \mathrm{~W} \mathrm{~h} \mathrm{~kg}^{-1}$ at a power density of $1017.1 \mathrm{~W} \mathrm{~kg}^{-1}$ and retained $77.8 \%$ of its initial capacitance after 3000 cycles.

\section{Experimental section}

\subsection{Materials preparation}

All chemicals used in this study were of analytical grade and were purchased from Sigma-Aldrich. NF were cleaned using acetone, concentrated $\mathrm{HCl}$, ethanol and deionized (DI) water for $15 \mathrm{~min}$. NiO nanosheets were synthesized directly on the NF $(2$ $\left.\times 2 \mathrm{~cm}^{2}\right)$ by immersing into the solution with $\mathrm{Ni}\left(\mathrm{NO}_{3}\right)_{2} \cdot 6 \mathrm{H}_{2} \mathrm{O}$ $(0.7 \mathrm{~g})$, urea $(0.2 \mathrm{~g})$, and ethanol $(40 \mathrm{~mL})$. The mixture was transferred into $50 \mathrm{~mL}$ autoclave with a Teflon liner at $180{ }^{\circ} \mathrm{C}$ and was then kept for $15 \mathrm{~h}$. The obtained product was washed in an ultrasound bath with ethanol and DI water and dried at $60^{\circ} \mathrm{C}$ for $12 \mathrm{~h}$. The samples were subsequently annealed in air at $300{ }^{\circ} \mathrm{C}$ for $3 \mathrm{~h}$ to obtain nickel foam-supported NiO nanosheet arrays. The area density of NiO was nearly $1.91 \mathrm{mg} \mathrm{cm}^{-2}$. Ag$\mathrm{NiO} / \mathrm{NF}$ was fabricated using the wet chemical reduction method. In a typical procedure, the as-prepared NiO/NF $(2 \times$ $\left.2 \mathrm{~cm}^{2}\right)$ was immersed in $\mathrm{AgNO}_{3}$ aqueous solution $(10 \mathrm{~mL}$, $0.01 \mathrm{M}$ ) and then heated at $100{ }^{\circ} \mathrm{C}$ for $5 \mathrm{~h}$. Finally, the sample was washed with DI water and dried at $60^{\circ} \mathrm{C}$ for $12 \mathrm{~h}$.

\subsection{Materials characterization}

The products were measured by X-ray diffraction (XRD) on a Rigaku MPA-2000 X-ray diffractometer with $\mathrm{Cu} \mathrm{K} \alpha$ radiation $(\lambda=1.5418 \AA)$ for the phase analysis. Scanning electron microscopy (SEM, Hitachi, S-4800) and transmission electron microscopy (TEM, FEI Talos, USA) were used to observe the morphology of the samples. X-ray photoelectron spectroscopy (XPS) was performed with the Thermo VG Escalab 250 photoelectron spectrometer.

\subsection{Electrochemical tests}

$\mathrm{Ag}-\mathrm{NiO} / \mathrm{NF}$ was directly used as the working electrode. Electrochemical measurements were carried out on an electrochemical working station (IviumNstat, Ivium Technologies) in a threeelectrode system. The electrolyte was $6.0 \mathrm{M} \mathrm{KOH}$ aqueous solution, and the solution was degased for $30 \mathrm{~min}$ using a sonicator. Saturated calomel electrode $\left(\mathrm{SCE}, \mathrm{Hg} / \mathrm{Hg}_{2} \mathrm{Cl}_{2}\right.$ ) and $\mathrm{Pt}$ electrode were used as the reference and counter electrode, respectively. Cyclic voltammetry (CV), galvanostatic charge/ discharge (GCD), and electrochemical impedance spectroscopy (EIS) were applied to confirm the capacitive behavior of Ag-NiO/NF electrodes. The EIS was conducted at an amplitude of $5 \mathrm{mV}$ in the frequency range of $100 \mathrm{kHz}$ to $10 \mathrm{mHz}$. The obtained GCD curves were used to calculate the specific capacitance $\left(C_{\mathrm{S}}\right)$ in accordance with the following equation: ${ }^{27}$ 


$$
C_{\mathrm{s}}=\frac{2 i_{\mathrm{m}} \int V \mathrm{~d} t}{V^{2} \mid \begin{array}{l}
V_{\mathrm{f}} \\
V_{\mathrm{i}}
\end{array}},
$$

where $i_{\mathrm{m}}=I / m\left(\mathrm{~A} \mathrm{~g}^{-1}\right)$ is the current density and $V(\mathrm{~V})$ is the potential window with initial $\left(V_{\mathrm{i}}\right)$ and final $\left(V_{\mathrm{f}}\right)$ values.

The performance of asymmetric SCs was also measured using CV and GCD. The anode electrode was fabricated mixing $85 \mathrm{wt} \%$ of rGO, $10 \% \mathrm{wt} \%$ of acetylene black, and $5 \%$ poly(tetrafluoroethylene). The energy $(E)$ and power $(P)$ densities were calculated using the following equations:

$$
\begin{gathered}
E=\frac{I \int V \mathrm{~d} t}{M}, \\
P=\frac{E}{\Delta t},
\end{gathered}
$$

where $M$ is the total mass of both positive and negative electrodes.

\section{Results and discussion}

$\mathrm{Ag}$ particles were synthesized by wet chemical reduction without the presence of reducing agents. Recently, Nishimura et al. demonstrated that $\mathrm{NaOH}$ accelerates the reduction of $\mathrm{Ag}^{+}$ions and nucleation of metallic Ag nanoparticles through the formation of $\mathrm{Ag}_{2} \mathrm{O}$ intermediate. ${ }^{28}$ In the current study, the $-\mathrm{OH}$ on the surface of $\mathrm{NiO}$ nanosheets caused the generation of $\mathrm{Ag}_{2} \mathrm{O}$ (eqn (4)). ${ }^{29}$ The self-redox reaction of $\mathrm{Ag}_{2} \mathrm{O}$ could occur under the influence of indoor light. The photo-generated electrons and holes in $\mathrm{Ag}_{2} \mathrm{O}$ could facilitate its redox reaction toward the generation of metallic Ag particles, as indicated in eqn (5) and (6).

$$
\begin{gathered}
\mathrm{Ag}^{+}+\mathrm{OH} \cdots \mathrm{NiO} \rightarrow \mathrm{AgOH} \cdots \mathrm{NiO} \rightarrow \mathrm{Ag}_{2} \mathrm{O} \cdots \mathrm{NiO} \\
\mathrm{Ag}_{2} \mathrm{O}+h v \text { (indoor light) } \rightarrow \mathrm{h}^{+}+\mathrm{e}^{-} \\
\mathrm{Ag}_{2} \mathrm{O}+\mathrm{h}^{+}+\mathrm{e}^{-} \rightarrow \mathrm{Ag}+\mathrm{O}_{2}
\end{gathered}
$$

Fig. 1 shows the XRD patterns of $\mathrm{NiO} / \mathrm{NF}$ and $\mathrm{Ag}-\mathrm{NiO} / \mathrm{NF}$. $\mathrm{NiO}$ was superimposed on the pattern of NF substrate
(Fig. 1a). The XRD peaks of the NiO nanosheets corresponded to the cubic NiO phase (JCPDS no. 65-2901) and confirmed the formation of a highly crystalline structure after annealing at $300{ }^{\circ} \mathrm{C}$. It was demonstrated that surface redox reactivity of an electrode material depends on its crystallinity, which can be optimized using the annealing temperature. ${ }^{30}$ Previous works have shown that $\mathrm{NiO}$ annealed at $300{ }^{\circ} \mathrm{C}$ presents the highest electrochemical performance. ${ }^{31,32}$ Fig. $1 \mathrm{~b}$ shows the XRD pattern of the Ag-NiO scraped from the substrate. The peaks located at around 38.1, 44.3, 64.5, and 77.4 could be indexed as the (111), (200), (220), and (311) planes of metal Ag (JCPDS no. 65-2871), respectively. The remaining diffraction peaks were consistent with the planes of NiO.

Fig. 2 shows the microstructures of $\mathrm{NiO} / \mathrm{NF}$ and $\mathrm{Ag}-\mathrm{NiO} / \mathrm{NF}$ at different magnifications. NF was used as the current collector and provided efficient pathway for electron transport and reduced the diffusion resistance of the electrode due to its high electrical conductivity and 3D cross-linked structure. ${ }^{33}$ After the solvothermal treatment and a subsequent annealing process, NiO nanosheets were grown uniformly on the nickel foam with a high density. These nanosheets possessed an average thickness of approximately $40 \mathrm{~nm}$. These nanosheets connected with one another and aligned vertically, thereby resulting in the formation of porous structures. The porous NiO nanosheet arrays could offer effective penetration of electrolyte and abundant electroactive sites for redox reactions. In addition, the interconnected arrays could maintain the structural stability by relaxing volume expansion during the charge/ discharge process. Compared with the SEM images of $\mathrm{NiO} / \mathrm{NF}$ and $\mathrm{Ag}-\mathrm{NiO} / \mathrm{NF}$ in Fig. 2b, the interconnected arrays of NiO nanosheet were fully retained and Ag particles were uniformly deposited on the surface of $\mathrm{NiO}$ nanosheet arrays. The $\mathrm{Ag}$ particles could act as bridge for electron transfer, thus, electrochemical performance of $\mathrm{NiO}$ nanosheets could be enhanced.

From the TEM image of Ag-NiO/NF sample, Ag particles were found loaded onto the surface of NiO nanosheet (Fig. 3a). Fig. $3 \mathrm{~b}$ elucidates the thin nature of $\mathrm{NiO}$ nanosheets by the folding silk-like morphology with curling folded edges and transparent feature. The selected-area electron diffraction (SAED, selected area: $\sim 200 \mathrm{~nm}$ in diameter) exhibited
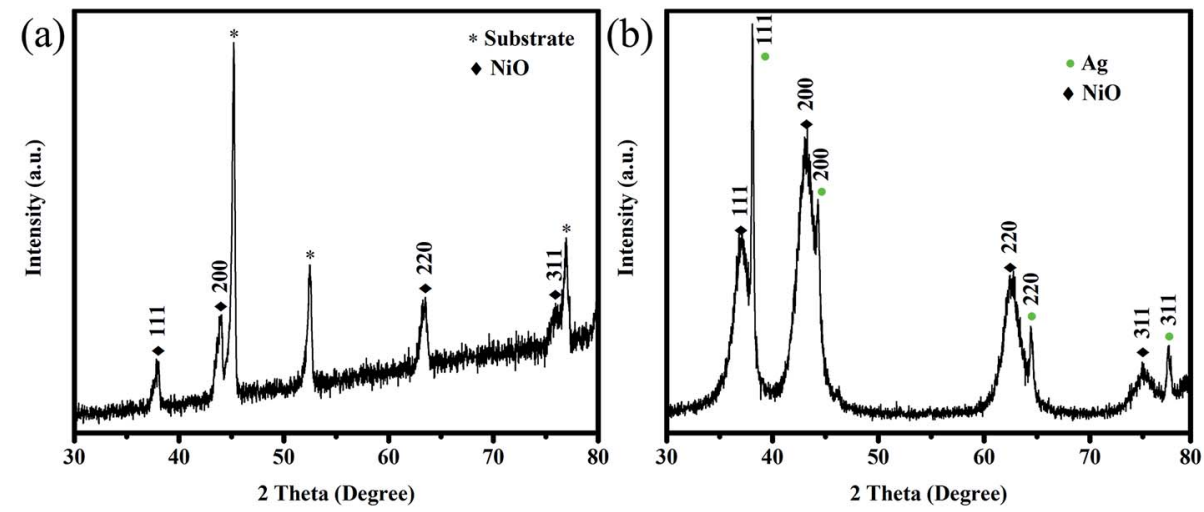

Fig. 1 XRD patterns of $\mathrm{NiO} / \mathrm{NF}$ (a) and Ag-NiO powder scraped from samples (b). 

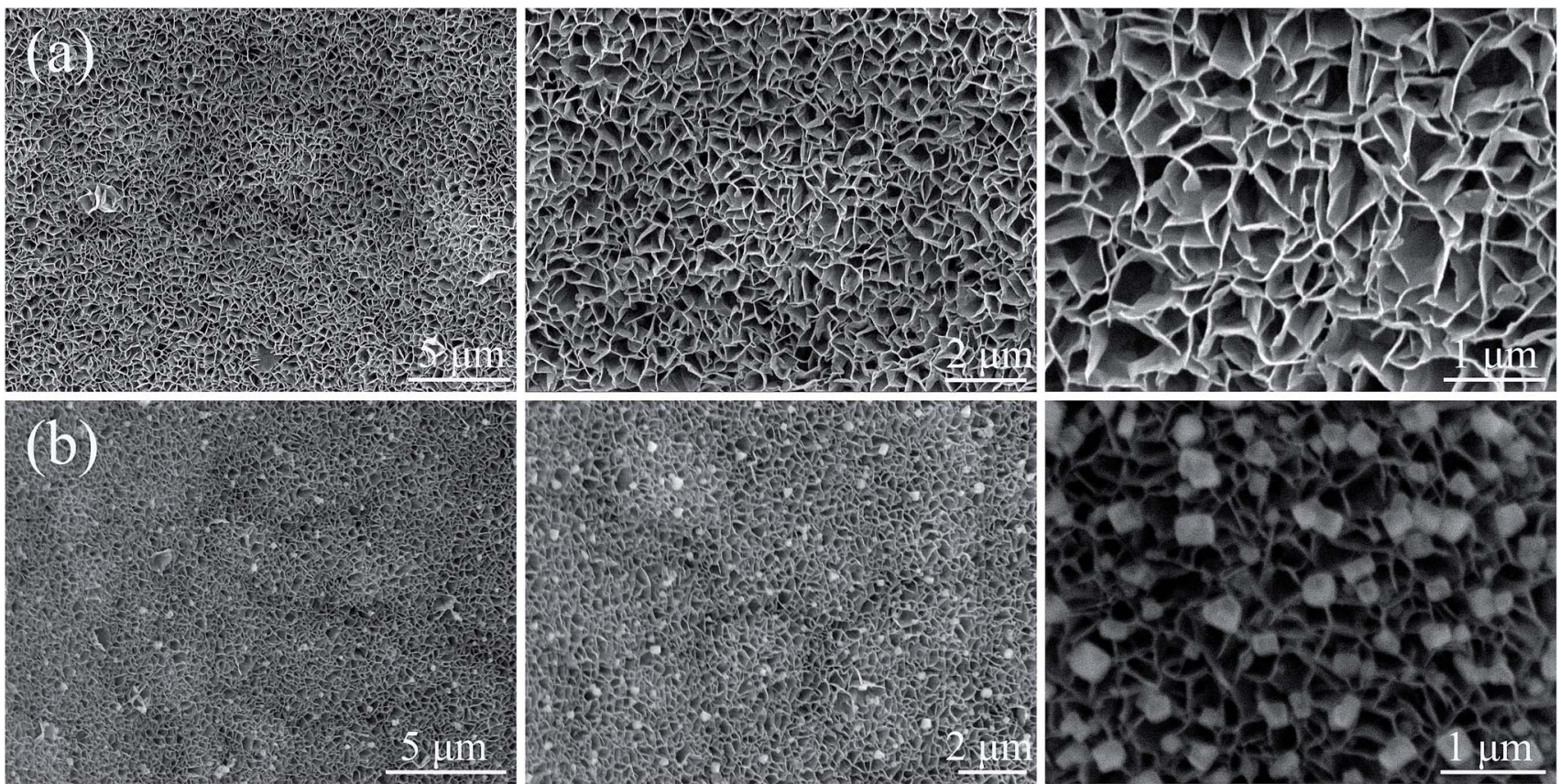

Fig. 2 SEM images of $\mathrm{NiO} / \mathrm{NF}$ (a) and $\mathrm{Ag}-\mathrm{NiO} / \mathrm{NF}$ (b) at different magnifications

polycrystalline rings, and the diffraction rings could be indexed as the (111), (200), (220), and (311) planes of the NiO phase

(Fig. 3c). Fig. 3d shows a typical high-resolution TEM (HRTEM) image of NiO nanosheets. The lattice spacing of $0.21 \mathrm{~nm}$ corresponded to the (200) plane of NiO. Fig. 3e shows the Ag particles of the surface of the NiO nanosheet. The lattice
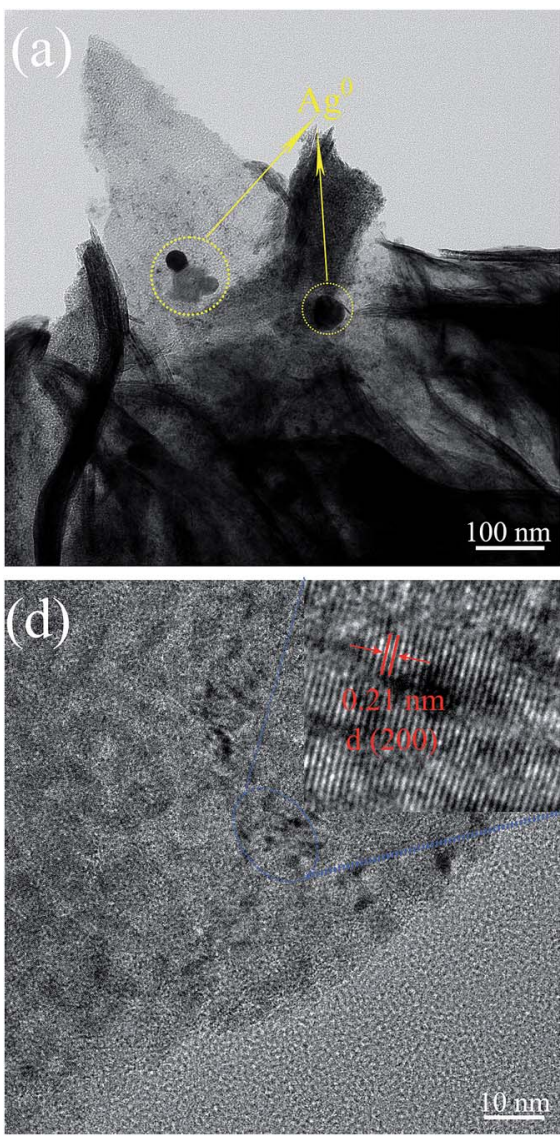
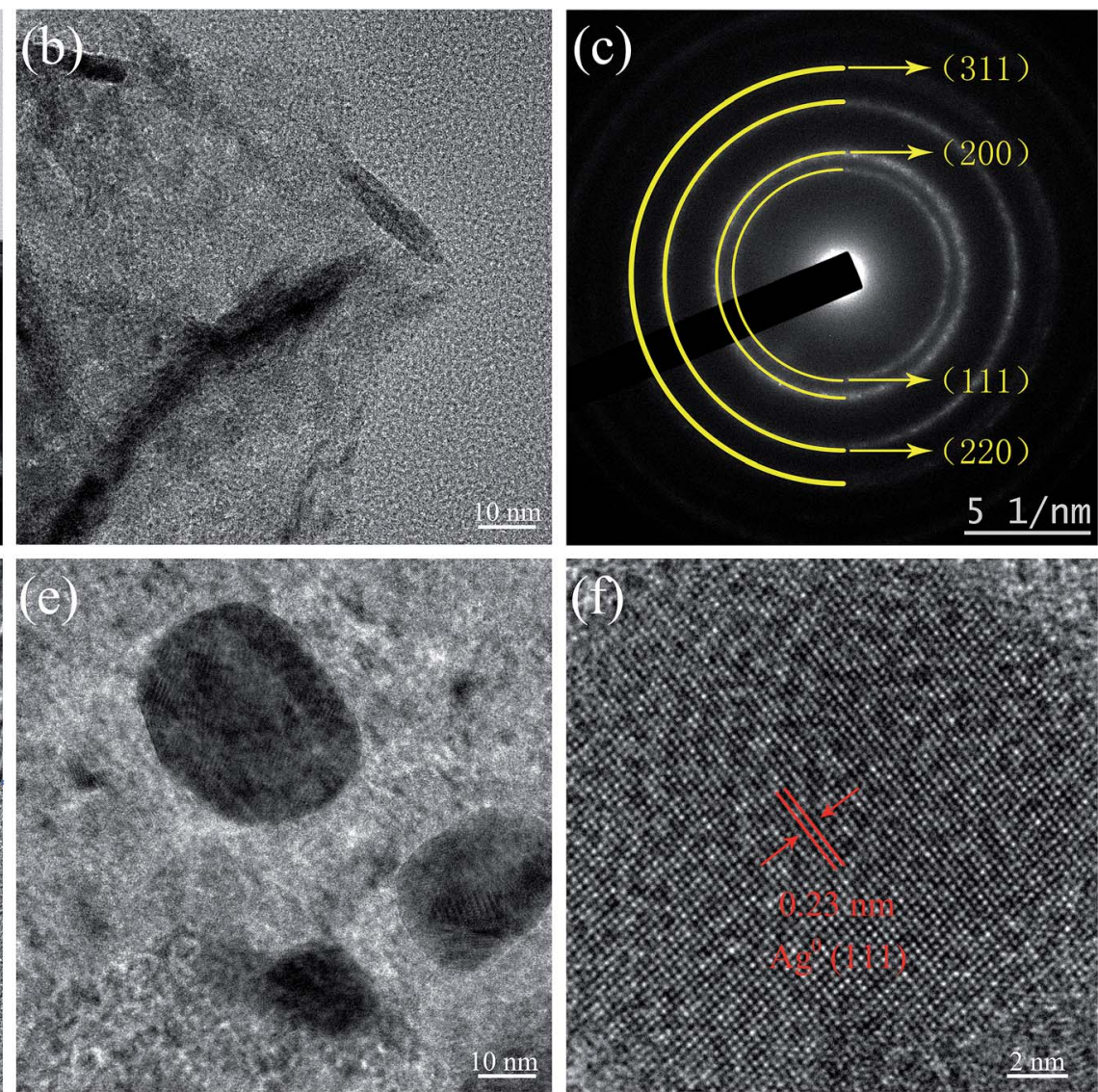

Fig. 3 TEM image of Ag-NiO/NF (a), HRTEM images ( $b$ and d) of NiO nanosheet, SAED pattern of NiO (c), and HRTEM images of metallic Ag (e and f). 
spacing was $0.23 \mathrm{~nm}$, which corresponded to the lattice spacing of the (111) planes for the Ag phase (Fig. 3f).

The surface states of Ag-NiO/NF were examined by XPS. The typical spectrum indicated the existence of $\mathrm{Ni}, \mathrm{Ag}, \mathrm{C}$ and $\mathrm{O}$ elements (Fig. 4a). The Ag 3d core level spectrum is shown in Fig. 4b. Two peaks observed at 374.2 and $368.1 \mathrm{eV}$ could be attributed to $\mathrm{Ag} 3 \mathrm{~d}_{3 / 2}$ and $\mathrm{Ag} 3 \mathrm{~d}_{5 / 2}$, respectively. These values and the $6.1 \mathrm{eV}$ splitting of the $3 \mathrm{~d}$ doublet signal suggest the existence of metallic $\mathrm{Ag}$, which also agree with previous reports. ${ }^{34,35}$

We further systematically studied the electrochemical performance of the electrodes in terms of CV, EIS, and GCD. Fig. 5a shows the CV curves of bulk NF, NiO/NF, and $\mathrm{Ag}-\mathrm{NiO} / \mathrm{NF}$ at a scan rate of $5 \mathrm{mV} \mathrm{s}^{-1}$. The straight line (flattened due to scale difference) was observed for pure NF; therefore, the capacitance of $\mathrm{NF}$ is negligible. In the case of $\mathrm{NiO} / \mathrm{NF}$ and $\mathrm{Ag}$ $\mathrm{NiO} / \mathrm{NF}$, well-defined redox from $0 \mathrm{~V}$ to $0.5 \mathrm{~V}$ versus SCE was observed, which originated from the faradaic reactions of $\mathrm{Ni}^{2+} /$ $\mathrm{Ni}^{3+}$ associated with $\mathrm{OH}^{-}$(eqn (7)). ${ }^{36}$

$$
\mathrm{Ni}^{2+}+\mathrm{OH}^{-} \leftrightarrow \mathrm{Ni}^{3+}+\mathrm{e}^{-}
$$

Notably, the $\mathrm{CV}$ curves of $\mathrm{NiO} / \mathrm{NF}$ and $\mathrm{Ag}-\mathrm{NiO} / \mathrm{NF}$ showed symmetrical shapes; therefore, the faradaic reaction of $\mathrm{Ni}^{2+} / \mathrm{Ni}^{3+}$ is responsible for the improved capacitance performance. The $\mathrm{CV}$ curves of $\mathrm{Ag}-\mathrm{NiO} / \mathrm{NF}$ electrode had a larger integral area than those of the NiO/NF electrode; therefore, $\mathrm{Ag}-\mathrm{NiO} / \mathrm{NF}$ electrode exhibits superior electrochemical capacitance. Furthermore, the high electrochemical properties of the $\mathrm{Ag}-\mathrm{NiO} / \mathrm{NF}$ electrode are attributed to the loading of $\mathrm{Ag}$ particles providing rapid electronic pathways. Fig. 5b shows the typical CV curves of assynthesized $\mathrm{Ag}-\mathrm{NiO} / \mathrm{NF}$ electrode at sweep rates of $5,10,30$, 50 , and $100 \mathrm{mV} \mathrm{s}^{-1}$. A pair of redox peaks with symmetric characteristic could be identified in the CV curves, suggesting a high reversibility of the fast charge/discharge response. The peak current significantly increased with the increase in sweep rate. The shape of the CV curves was insignificantly influenced by the increasing sweep rate due to the enhanced electrolyte ions diffusion from open 2D structure of $\mathrm{NiO}$ nanosheets and the superior electronic conductivity of NF and Ag particles.
Fig. 5c shows the GCD curves of the Ag-NiO/NF electrode at different current densities in the range of $1-20 \mathrm{~A} \mathrm{~g}^{-1}$ in a potential window of $0-0.4 \mathrm{~V}$. A distinct plateau could be observed in the GCD curves, which corresponded to the forward reaction in eqn (7). ${ }^{37}$ The GCD curves displayed great symmetry; therefore, excellent reversible redox reactions occur. The gravimetric capacitances of $\mathrm{NiO} / \mathrm{NF}$ electrode (Fig. $\mathrm{S} 1 \dagger$ ) and $\mathrm{Ag}-\mathrm{NiO} /$ NF electrode (Fig. 5d) were further calculated and plotted as a function of current density. The specific capacitances of Ag$\mathrm{NiO} / \mathrm{NF}$ electrode were 1254.9, 1183.2, 1137.6, 1054.6, and 914.3 $\mathrm{F} \mathrm{g}^{-1}$ at different current densities of 1, 3, 5, 10, and $20 \mathrm{~A}$ $\mathrm{g}^{-1}$, respectively. Impressively, Ag-NiO/NF electrode preserved approximately $73 \%$ of specific capacitance delivered at $1 \mathrm{Ag}^{-1}$ as the current density increased to $20 \mathrm{~A} \mathrm{~g}^{-1}$, indicating high-rate capability. The increase in current density led to the decrease in specific capacitance, which was probably caused by the resistance of $\mathrm{NiO}$ nanosheets and the insufficient faradaic redox reaction of $\mathrm{NiO}$ nanosheets under high discharge current densities.

In EIS spectrum, the intercept of the curve at the real $Z^{\prime}$ axis at high frequencies represents the resistance of the electrochemical system $\left(R_{\mathrm{S}}\right)$ and the semicircular diameter reflect the charge-transfer resistance $\left(R_{\mathrm{ct}}\right)$; meanwhile, at a low frequency, the slope of the spike indicates the ion diffusion. The Nyquist plots of $\mathrm{NiO} / \mathrm{NF}$ electrode and $\mathrm{Ag}-\mathrm{NiO} / \mathrm{NF}$ electrode are shown in Fig. 5e. The Nyquist plots exhibited one semicircle in the high frequency region and an inclined line in the low-frequency region. $R_{\mathrm{s}}$ for $\mathrm{Ag}-\mathrm{NiO} / \mathrm{NF}$ electrode was 0.39 , which is lower than that of $\mathrm{NiO} / \mathrm{NF}$ electrode $(0.46)$; therefore, the $\mathrm{Ag}-\mathrm{NiO} / \mathrm{NF}$ electrode exhibits high conductivity. The small diameter of the semicircle suggested that $\mathrm{Ag}$ particles in the $\mathrm{Ag}-\mathrm{NiO} / \mathrm{NF}$ electrode presented a satisfactory electron pathway for efficient electron transport. In the low-frequency region, EIS of Ag$\mathrm{NiO} / \mathrm{NF}$ electrode presented a more vertical straight line along the imaginary axis, implying lower diffusion resistance of the structure.

The specific capacitances were plotted against the number of the GCD cycles for up to 3000 cycles to determine the stability of the electrodes (Fig. 5f). The retention of specific capacitance of $\mathrm{Ag}-\mathrm{NiO} / \mathrm{NF}$ electrode was $83.2 \%$ after 3000 cycles, which is
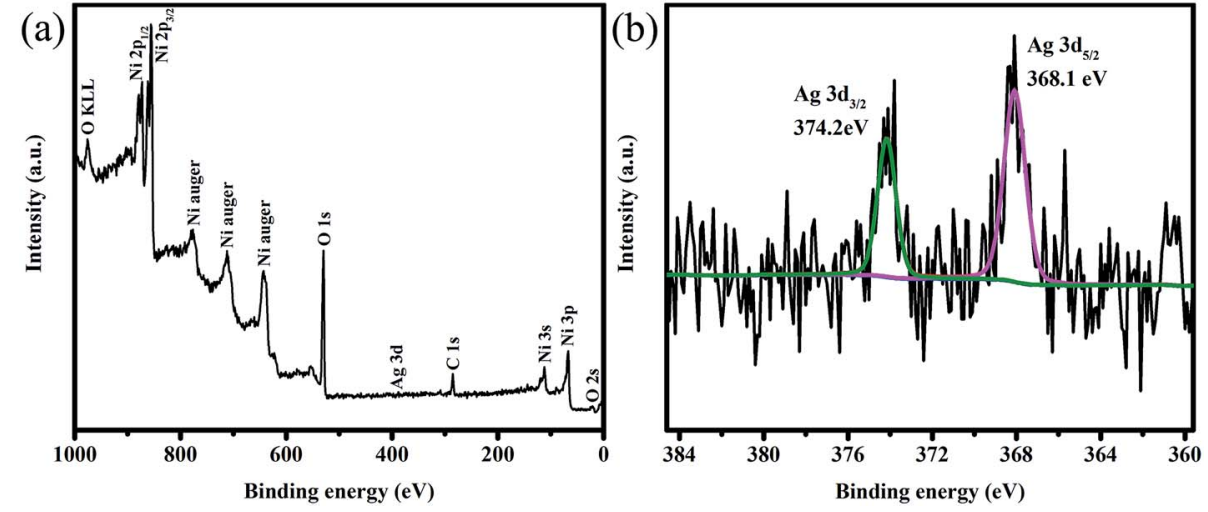

Fig. 4 XPS survey spectra of Ag-NiO/NF (a) and high-resolution XPS spectrum of $\mathrm{Ag} \mathrm{3d}(\mathrm{b})$. 

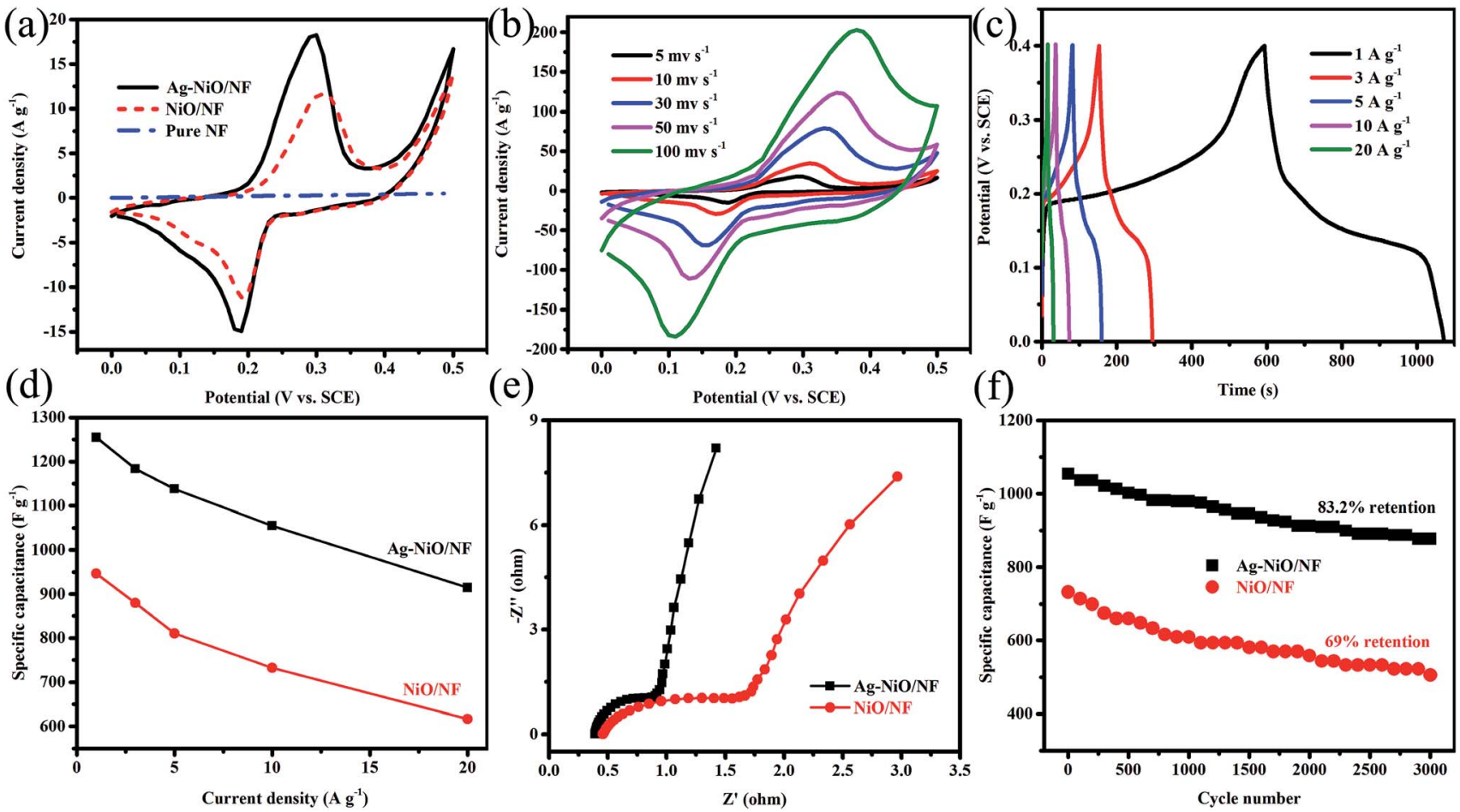

Fig. $5 \mathrm{CV}$ curves of $\mathrm{Ag}-\mathrm{NiO} / \mathrm{NF}$ compared with $\mathrm{NiO} / \mathrm{NF}$ and $\mathrm{NF}$ at a scan rate of $5 \mathrm{mV} \mathrm{s}^{-1}$ (a), CV curves of the Ag-NiO/NF at different scan rates (b), GCD curves of $\mathrm{Ag}-\mathrm{NiO} / \mathrm{NF}$ at various current densities (c), specific capacitance of Ag-NiO/NF and NiO/NF at different current densities (d), Nyquist plots of $\mathrm{Ag}-\mathrm{NiO} / \mathrm{NF}$ and $\mathrm{NiO} / \mathrm{NF}$ (e), and cycling performance of $\mathrm{Ag}-\mathrm{NiO} / \mathrm{NF}$ and $\mathrm{NiO} / \mathrm{NF}$ (f).

higher than that of $\mathrm{NiO} / \mathrm{NF}(69 \%)$. The above-mentioned electrochemical testing results suggested that $\mathrm{Ag}-\mathrm{NiO} / \mathrm{NF}$ electrode possessed high specific capacitances and great cycling stability. This high electrochemical performance could be attributed to the unique features of the electrode as follows: (1) the direct growth of NiO nanosheets on NF generated binder-free electrode and the binder-free electrode not only reduced the "dead volume" but also favored the electron transfer; (2) the electrochemically active sites of the NiO nanosheets could be efficiently exposed to the electrolyte due to their 2D structure; (3) the interconnecting network provided continuous electron conducting pathways; ${ }^{38}(4)$ the excellent adhesion between NiO nanosheet arrays and NF ensured the structural integrity; (5) the presence of $\mathrm{Ag}$ particles provided the least resistance path electron, thereby improving the specific capacitance.

ASC devices were fabricated using the as-prepared $\mathrm{Ag}-\mathrm{NiO} /$ $\mathrm{NF}$ and rGO as the cathode and anode electrodes, respectively. A piece of polypropylene paper was used as the separator. Both electrodes were immersed into $6 \mathrm{M} \mathrm{KOH}$ along with separator and packed into CR2032 full cell (Fig. 6a). The specific capacitance of the rGO electrode was $178 \mathrm{~F} \mathrm{~g}^{-1}$ when the current density was $1 \mathrm{~A} \mathrm{~g}^{-1}$. CV curves of Ag-NiO/NF electrodes and $\mathrm{rGO}$ electrodes at a scan rate of $5 \mathrm{mV} \mathrm{s}^{-1}$ revealed that the $\mathrm{Ag}-\mathrm{NiO} / \mathrm{NF}$ electrodes and $\mathrm{rGO}$ electrodes have stable potential windows of $0-0.5 \mathrm{~V}$ and $-1-0 \mathrm{~V}$, respectively (Fig. $6 \mathrm{~b}$ ). According to the equation $\frac{1}{C_{\text {total }}}=\frac{1}{C_{\text {cathode }}}+\frac{1}{C_{\text {anode }}}$, the charge storage capacity of cathode and anode electrodes should be balanced to obtain a high electrochemical performance. The charge balance between the two electrodes should follow the equation $q^{+}=q^{-}$. The stored charge is related to the specific capacitance $(C)$, the potential windows obtained in the three-electrode measure $(\Delta V)$, and the mass of the electrodes $(m)$, which follows the relationship $q=C \times \Delta V \times m$. the NiO to rGO mass ratio was calculated by the following equation: $\frac{m^{+}}{m^{-}}=\frac{C^{-} \times \Delta V^{-}}{C^{+} \times \Delta V^{+}}$. The $\mathrm{NiO}$ to rGO mass ratio was adjusted to be $2.8: 1$.

Fig. 6c shows typical CV curves for the $\mathrm{Ag}-\mathrm{NiO} / \mathrm{NF} / / \mathrm{rGO}^{7} \mathrm{ASC}$ in $6 \mathrm{M} \mathrm{KOH} \mathrm{(aq)} \mathrm{electrolyte} \mathrm{at} \mathrm{various} \mathrm{scan} \mathrm{rates} \mathrm{in} \mathrm{the} \mathrm{range}$ from $0-1.4 \mathrm{~V}$. Two redox peaks were observed, and they suggested the faradaic capacitance nature of the $\mathrm{Ag}-\mathrm{NiO} / \mathrm{NF} / / \mathrm{rGO}$ capacitor arising from the Ag-NiO/NF electrode. GCD curves at different current densities from $1 \mathrm{~A} \mathrm{~g}^{-1}$ to $20 \mathrm{~A} \mathrm{~g}^{-1}$ are shown in Fig. 6d. No obvious $I r$ drop was observed, suggesting a low internal resistance for the ASC. The GCD curves exhibited symmetric profiles, indicating an excellent electrochemical reversibility. The relationship between specific capacitance and current density is plotted in Fig. S2. $\dagger$ The calculated specific capacitances of the ASC (based on the total mass of the active materials of the two electrodes) were 97.9, 86.0, 73.4, 67.3, and $52.9 \mathrm{~F} \mathrm{~g}^{-1}$ at $1,3,5,10$, and $20 \mathrm{~A} \mathrm{~g}^{-1}$, respectively; therefore, the ASC presents high-rate capability.

Energy and power densities are two important parameters that can be used to evaluate the electrochemical performance of a full cell. The Ragone plot of Ag-NiO/NF//rGO ASC device based on GCD measurements is shown in Fig. 6e. A maximum energy density of $26.7 \mathrm{~W} \mathrm{~h} \mathrm{~kg}^{-1}$ was obtained at power density of $1017.1 \mathrm{~W} \mathrm{~kg}^{-1}$. The energy density was maintained at $14.4 \mathrm{~W} \mathrm{~h} \mathrm{~kg}^{-1}$ when 


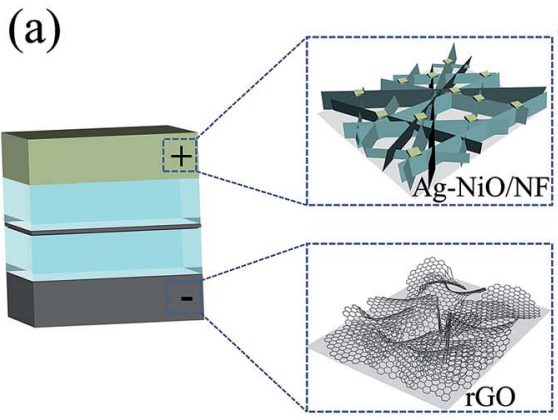

(d)

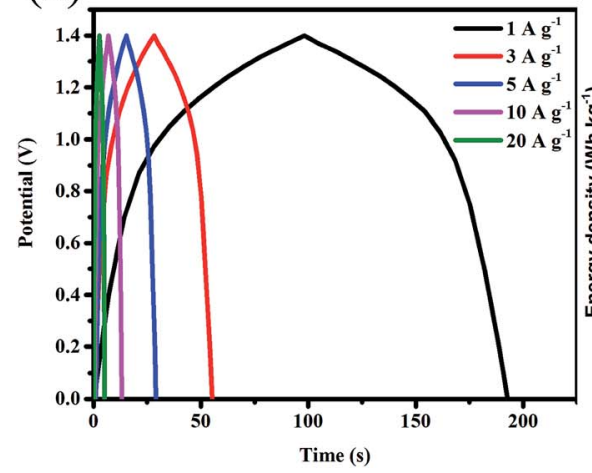

(b)

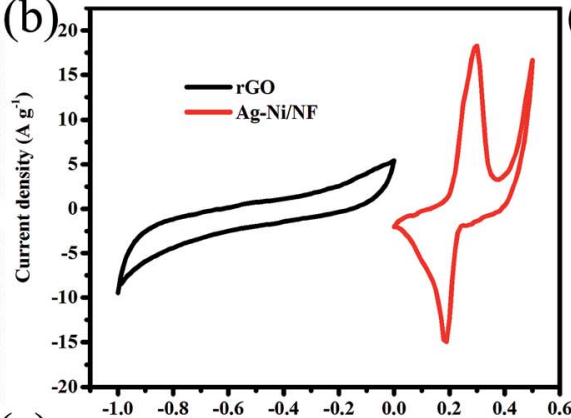

(e)

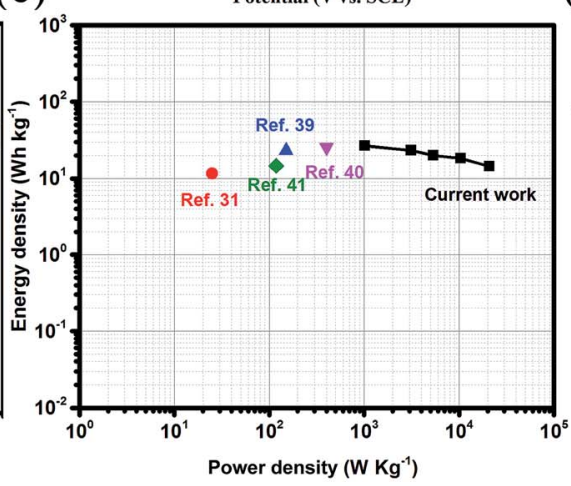

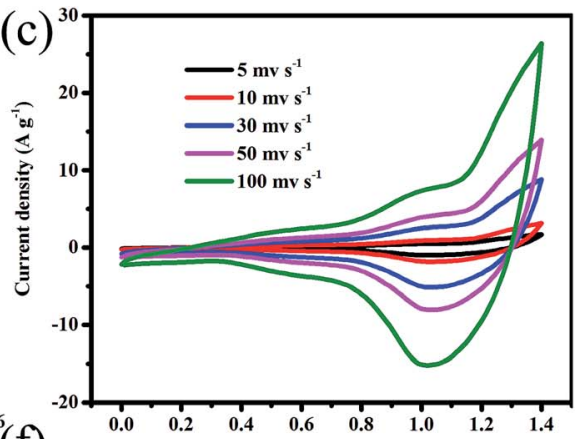

(f)

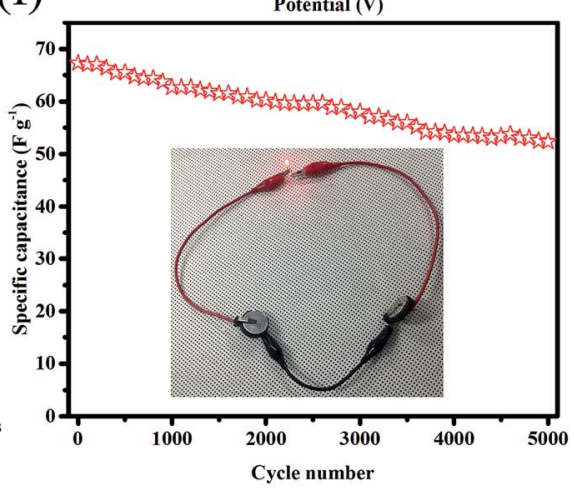

Fig. 6 Schematic of the as-assembled Ag-NiO/NF//rGO ASC device (a), comparative CV curves of Ag-NiO/NF and rGO in a three-electrode system at a scan rate of $5 \mathrm{mV} \mathrm{s}^{-1}$ (b), CV (c) and GCD (d) curves of Ag-NiO/NF//rGO ASC device at different scan rates, Ragone plot of the Ag$\mathrm{NiO} / \mathrm{NF} / / \mathrm{rGO}$ ASC device in comparison with that of many previously reported asymmetric SCs (e), and cycling stability over 5000 cycles, inset shows an LED lit by two series connected ASC devices (f).

the power density increased to $20869.6 \mathrm{~W} \mathrm{~kg}^{-1}$. The energy and power densities of our ASC device were superior to those of many other previously reported NiO-based ASCs, such as $\mathrm{NiO} / / \mathrm{C}$

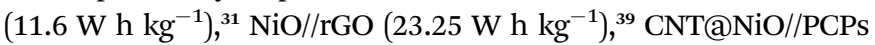
(25.4 W h kg $\left.{ }^{-1}\right),{ }^{40} \mathrm{NiO} / / \mathrm{C}\left(14.6 \mathrm{~W} \mathrm{~h} \mathrm{~kg}^{-1}\right) .{ }^{41}$ Cycling performance was measured by charging and discharging the devices 3000 times at a current density $10 \mathrm{~A} \mathrm{~g}^{-1}$ (Fig. 6f). A total of $77.8 \%$ of initial capacitance of the device remained after 3000 charge/discharge cycles. The applicability could be proved visibly by powering red light-emitting diodes (LEDs). The serially connected two ASC devices lighted up the commercial LED, as displayed in the inset of Fig. $6 f$.

\section{Conclusions}

In this study, surface loading of $\mathrm{NiO} / \mathrm{NF}$ with $\mathrm{Ag}$ particles was prepared using a wet chemical method. NiO nanosheet arrays were grown vertically on the NF, which served as a conducting scaffold to improve the conductive nature. The anchored Ag particles further increased the electronic conductivity. The electrochemical properties of the $\mathrm{Ag}-\mathrm{NiO} / \mathrm{NF}$ electrode resulted in superior specific capacitance of $1254.9 \mathrm{~F} \mathrm{~g}^{-1}$ at $1 \mathrm{~A} \mathrm{~g}^{-1}$ over that of the $\mathrm{NiO} / \mathrm{NF}\left(946.3 \mathrm{~F} \mathrm{~g}^{-1}\right)$ at a current density of $1 \mathrm{~A} \mathrm{~g}^{-1}$. Furthermore, ASC devices were assembled with Ag-NiO/NF and rGO in $6 \mathrm{M} \mathrm{KOH}$. The ASC device delivered a high energy density of $26.7 \mathrm{~W} \mathrm{~h} \mathrm{~kg}^{-1}$ and the power density of $20869.6 \mathrm{~W} \mathrm{~kg}^{-1}$ with the potential window of $1.4 \mathrm{~V}$. Moreover, the assembled devices exhibited a good cycling stability with $77.8 \%$ initial capacitance retention after 3000 cycles.

\section{Conflicts of interest}

There are no conflicts to declare.

\section{Acknowledgements}

This work was supported by the Global Frontier hybrid Interface Materials (GFHIM) program of the National Research Foundation of Korea (NRF) funded by the Ministry of Science, ICT \& Future Planning (2013M3A6B1078874), the Science and Technology Development Fund from Macau SAR (FDCT-098/2015/ A3) and the UEA funding.

\section{References}

1 C. Merlet, B. Rotenberg, P. A. Madden, P. L. Taberna, P. Simon, Y. Gogotsi and M. Salanne, Nat. Mater., 2012, 11, 306-310.

2 P. Simon and Y. Gogotsi, Nat. Mater., 2008, 7, 845-854.

3 B. E. Conway, V. Birss and J. Wojtowicz, J. Power Sources, 1997, 66, 1-14.

4 Z. S. Wu, W. C. Ren, D. W. Wang, F. Li, B. L. Liu and H. M. Cheng, ACS Nano, 2010, 4, 5835-5842. 
5 J. Yan, Q. Wang, T. Wei and Z. J. Fan, Adv. Energy Mater., 2014, 4, 1300816.

6 S. X. Wu, K. S. Hui and K. N. Hui, J. Phys. Chem. C, 2015, 119, 23358-23365.

7 S. X. Wu, K. S. Hui, K. N. Hui and K. H. Kim, J. Mater. Chem. A, 2016, 4, 9113-9123.

8 Z. J. Gu, L. Yan, G. Tian, S. J. Li, Z. F. Chai and Y. L. Zhao, Adv. Mater., 2013, 25, 3758-3779.

9 M. J. Zhi, C. C. Xiang, J. T. Li, M. Li and N. Q. Wu, Nanoscale, 2013, 5, 72-88.

10 M. Huang, F. Li, J. Y. Ji, Y. X. Zhang, X. L. Zhao and X. Gao, CrystEngComm, 2014, 16, 2878-2884.

11 Y. X. Zhang, M. Kuang and J. J. Wang, CrystEngComm, 2014, 16, 492-498.

12 G. H. Lee, Y. W. Cheng, C. V. Varanasi and J. Liu, J. Phys. Chem. C, 2014, 118, 2281-2286.

13 G. H. Yuan, Z. H. Jiang, A. Aramata and Y. Z. Gao, Carbon, 2005, 43, 2913-2917.

14 M. Zhou, Y. F. Deng, K. Liang, X. J. Liu, B. Q. Wei and W. C. Hu, J. Electroanal. Chem., 2015, 742, 1-7.

15 J. Y. Cheng, B. Zhao, W. K. Zhang, F. Shi, G. P. Zheng, D. Q. Zhang and J. H. Yang, Adv. Funct. Mater., 2015, 25, 7381-7391.

16 S. J. Kim, G. J. Park, B. C. Kim, J. K. Chung, G. G. Wallace and S. Y. Park, Synth. Met., 2012, 161, 2641-2646.

17 N. B. Trung, T. V. Tam, D. K. Dang, K. F. Babu, E. J. Kim, J. Kim and W. M. Choi, Chem. Eng. J., 2015, 264, 603-609.

18 H. Jiang, P. S. Lee and C. Z. Li, Energy Environ. Sci., 2013, 6, 41-53.

19 C. X. Hu, S. J. He, S. H. Jiang, S. L. Chen and H. Q. Hou, RSC $A d v .$, 2015, 5, 14441-14447.

20 M. J. Deng, C. Z. Song, C. C. Wang, Y. C. Tseng, J. M. Chen and K. T. Lu, ACS Appl. Mater. Interfaces, 2015, 7, 9147-9156.

21 Z. Gonzalez, A. J. Sanchez-Herencia, B. Ferrari, A. Caballero and J. Morales, Key Eng. Mater., 2015, 2016, 58-64.

22 M. Usman, L. J. Pan, A. Sohail, Z. Mahmood and R. X. Cui, Chem. Eng. J., 2017, 311, 359-366.

23 R. Chadha, N. Maiti and S. Kapoor, Mater. Sci. Eng., C, 2014, 38, 192-196.
24 X. M. Wu, Z. Q. He, S. Chen, M. Y. Ma, Z. B. Xiao and R. Ben Liu, Mater. Lett., 2006, 60, 2497-2500.

25 M. Vanitha, Keerthi, P. Cao and N. Balasubramanian, J. Alloys Compd., 2015, 644, 534-544.

26 L. B. Ma, X. P. Shen, Z. Y. Ji, G. X. Zhu and H. Zhou, Chem. Eng. J., 2014, 252, 95-103.

27 L. Q. Mai, A. Minhas-Khan, X. C. Tian, K. M. Hercule, Y. L. Zhao, X. Lin and X. Xu, Nat. Commun., 2013, 4, 2923.

28 S. Nishimura, D. Mott, A. Takagaki, S. Maenosono and K. Ebitani, Phys. Chem. Chem. Phys., 2011, 13, 9335-9343.

29 C. P. Chen, P. Gunawan, X. W. Lou and R. Xu, Adv. Funct. Mater., 2012, 22, 780-787.

30 W. Xing, F. Li, Z. F. Yan and G. Q. Lu, J. Power Sources, 2004, 134, 324-330.

31 D. W. Wang, F. Li and H. M. Cheng, J. Power Sources, 2008, 185, 1563-1568.

32 K. W. Nam and K. B. Kim, J. Electrochem. Soc., 2002, 149, A346-A354.

33 S. M. Chen, G. Yang, Y. Jia and H. J. Zheng, ChemElectroChem, 2016, 3, 1490-1496.

34 J. K. Gan, Y. S. Lim, N. M. Huang and H. N. Lim, RSC Adv., 2015, 5, 75442-75450.

35 H. Xia, C. Y. Hong, X. Q. Shi, B. Li, G. L. Yuan, Q. F. Yao and J. P. Xie, J. Mater. Chem. A., 2015, 3, 1216-1221.

36 Q. Lu, M. W. Lattanzi, Y. P. Chen, X. M. Kou, W. F. Li, X. Fan, K. M. Unruh, J. G. G. Chen and J. Q. Xiao, Angew. Chem., Int. Ed., 2011, 50, 6847-6850.

37 B. Wang, J. S. Chen, Z. Y. Wang, S. Madhavi and X. W. Lou, Adv. Energy Mater., 2012, 2, 1188-1192.

38 M. Huang, F. Li, F. Dong, Y. X. Zhang and L. L. Zhang, J. Mater. Chem. A, 2015, 3, 21380-21423.

39 X. C. Ren, C. L. Guo, L. Q. Xu, T. T. Li, L. F. Hou and Y. H. Wei, ACS Appl. Mater. Interfaces, 2015, 7, 1993019940.

40 H. Yi, H. W. Wang, Y. T. Jing, T. Q. Peng and X. F. Wang, J. Power Sources, 2015, 285, 281-290.

41 G. H. Cheng, Q. G. Bai, C. H. Si, W. F. Yang, C. Q. Dong, H. Wang, Y. L. Gao and Z. H. Zhang, RSC Adv., 2015, 5, 15042-15051. 